\title{
Study on the Strategy for the Construction of Physical Education Practice Base
}

\author{
Gao Zhi \\ Physical Education College of Wuhan Institute of \\ Physical Education, \\ Wuhan 430079
}

\author{
Xu Qiong \\ Gymnastics College of Wuhan Institute of Physical \\ Education \\ Wuhan 430079
}

\begin{abstract}
The thesis performed the studies for the construction of physical education basis on below aspects: strengthen the ideological construction through deepening the understanding for education practice; establish excellent instructing teacher teams; comprehensively improve the comprehensive qualities of the interns; actively support the material construction of the practice bases like the sports facilities; establish and improve the rules and regulations for the education practice to achieve the standardization and systematization of practice work; establish the system of "contact point and contact person" system and strengthen the exchanges and communications among various bases to promote the mutual development; take full advantages of the multi-function of the bases; and strive to achieve the "three-party" joint construction of practice bases among the physical education institutes or departments, education administrative authority and the school for internship.
\end{abstract}

Keywords-Physical Education; Practice Base; Construction; Strategy

\section{INTRODUCTION}

The quality of the talents in the field of physical education is the most critical factor for the healthy development of the physical education undertaking of our country. The posture shall be taken by the physical education base in front of the new challenge is a major topic for the cultivation of sports talents and a critical process for improving the physical education practice quality and cultivating high quality sports talents. Moreover, the physical education practice base is also the best approach to get out of the dilemma of practice and improve the practice quality, as well the material basis for the guarantee of the social practice quality of physical education. In order to implement the idea of "quality education", establish the guiding ideology of "health first" and bring up major driving force for the basic physical education reform, together with the comprehensive considerations of the actual situations and major problems in the current construction of physical education bases in sports colleges, the study of the strategy for the construction of physical education base was conducted on below aspects.

\section{DEEPEN THE UNDERSTANDING TO THE EDUCATION PRACTICE WORK AND STRENGTHEN THE CONSTRUCTION OF IDEOLOGY}

It was found from the discussions and interviews with the leaders in the education practice bases that the understanding for educational practice work of the base schools experienced the process from liberty, unification and improvement: i) Primary construction stage: Some schools lacked abundant understanding for the undertaking of practice work, and some even took the practice tasks as an unnecessary burden, which resulted in the reluctance in accepting the practice tasks. There were mainly four reasons for such wrong understandings to education practice. First, they worried the intern would interfere the normal teaching orders after entering into their schools. Second, they worried the introduction of interns would have negative impacts to the teaching quality. Third, the introduction of the interns would increase the working burden of their schools. Finally, they had prejudice to the position of physical education. ii) The unification stage: The physical education institutes or departments took the measures like strengthen the teaching organization and management ability of the interns, improve the intern conditions through the implementation of base construction and so forth, which had made the school for practice realize that the construction of practice bases and undertaking of education practice work were beneficial for the teacher construction, exchange of teaching reform information and improvement of the school running conditions. iii) The improvement stage: Along with the standardization process of the education practice, the school for practice realized the benefits from the acceptance of interns were much higher than the disadvantages suffered. The awareness of the importance of physical education practice drove their actions in supporting the practice tasks, which had largely promoted the construction of the education practice. Meanwhile, the construction of education practice also needs the supports and cooperation of the physical education colleges, education administrative authorities, practice schools, local governments and etc. The key issue for the strategy of practice base construction is to motivate the enthusiasm of the practice schools based on the principle of mutual benefit and reciprocity. 


\section{ESTABLISH EXCELLENT INSTRUCTING TEACHER TEAM}

The selection and training of the leading teachers and instructing teachers is another key content for the construction of the education practice bases. In order to achieve exception results from education practice, it is mandatory to select the teachers with high ideological quality, strong business skills and abundant practice instructing experience as the leading or instructing teachers. The physical education institutes or departments shall not only stress on the cultivation and selection of their own leading teachers for the interns, but also shall attach high importance to the training of the instructing teachers in the practice schools. The physical education institutes or departments shall perform deep studies to the practice schools and perform deep studies for the practice tasks together with the practice schools to introduce the competition mechanism and change their positions from passive to positive.

Establish the relative stable education intern team with the concurrent considerations of the hierarchical structure with senior, middle-aged and young leading teacher and instructing teacher teams, and strengthen the selection and training of the middle-aged and young teachers. The leading teacher teams with high quality are the important safeguards for the smooth completion of the education internship tasks. The construction for leading teacher teams could be achieved through below approaches: i) Prepare the management system for the leading teachers and define the duties and responsibilities of the leading teachers; ii) strengthen the comprehensive assessment and in time feedback system for the competence and organization and coordination capacity of the leading teachers; iii) further improve the assessment standards for the leading teachers to link the assessment performance with the economic benefits, formulate the reward and punishment measures, and introduce the competition and appointment mechanism. The emphasis shall not only be on the selection and training of the leading teachers in the own departments, but also on the training on the instructing teachers of the practice schools. The physical education institutes or departments shall perform deep study on the practice schools and introduce competition mechanism for the selection of the practice schools.

\section{COMPREHENSIVELY IMPROVE THE}

\section{COMPREHENSIVE QUALITIES OF THE INTERNS}

Below measures could be taken to strengthen the professional skill training for the student normal schools and improve the comprehensive abilities of the interns: i) organize the interns to study internship documents, understand the spirit of the documents, improve the thinking and understanding, correct the study attitude and establish the self-confidence; ii) strengthen the training on the basic skills and the teaching abilities like practice on the queue formations, broadcast exercises, simulated teaching and so forth to enhance the comprehensive qualities of the interns and make preparations for their tasks during the internship period; iii) make preparations for the daily used articles to provide material safeguard for the smooth completion of the practice.

\section{ACTIVELY SUPPORT THE MATERIAL CONSTRUCTIONS OF THE PRACTICE BASE LIKE THE SPORTS FACILITIES}

First, on the aspect of educational investment, the method of "five-little money" (a little portion of fund from the provincial education department, a little portion of fund from physical education institutes, a little portion of fund from municipal education committee, a little proportion of fund from local government and a little proportion of fund from the school for internship) could be taken to strengthen the investment in the practice bases, enrich the fundamental construction of the practice base and improve the necessary facilities for practice. The construction of the material conditions of the education practice bases needs the common endeavor of various parties. The construction shall get the supports and assistance from the education administrative authorities. The physical education institute shall strive to get the assistance on the aspect of funds and materials from various authorities. Target hitting activities shall be performed for the practice bases. The practice schools shall endeavor to get the supports and help from the local government and optimize the school running and practice conditions by fund raising via various channels. The physical education institutes shall establish frequent communication mechanism with the practice schools, and provide the supports and convenience to the practice schools on the aspect of human resource, materials and capital. Besides, it is also necessary to develop the creativities of the students and teachers to develop and amend the sports programs, excavate and transform the traditional program with local features, produce simples teaching tools and so forth according to the actual status of the practice schools.

\section{ESTABLISH AND IMPROVE THE RULES AND REGULATIONS FOR EDUCATION PRACTICE TO REACH THE STANDARDIZATION AND SYSTEMATIZATION OF PRACTICE WORK}

The practice bases shall not only strictly implement the "Education Practice Proposal" of the physical education institutes, but also shall formulate a set of perfect management system for the education practice according to the actual status of their schools to perform dual-management for the interns, which would be beneficial for promoting the education practice to become an essential part of the teaching plan management of both the higher physical education institutes and the practice schools. Establish and improve the assessment system and incentive mechanism for the education practice, strengthen the material rewards for the instructing teachers with excellent performance, and enrich more connotations to the honor of "excellent intern". Establish the internal management system of "Level-to-level Management and Sharing of Responsibility". Systematic and standard management system is the organization guarantee for the smooth completion of the practice, as well as the main task for the construction of the education practice bases. Under the leadership of the Education Practice Steering Committee, the physical education institutes shall perform periodical practice studies, train the leading 
teacher and the team leader the interns, and conduct training to the interns about the teaching methods. The physical education institutes shall organize and motivate the interns and create favorable farewell atmosphere for the interns before the starting of the practice, strength the visits and communications with the interns to help them solve the practical problems during the practice process, and organize the practice result reporting meetings and reward the excellent interns and leading teachers upon the completion of the practice tasks. The person in charge of the local policy shall concern, support and supervise the education practice work. The base schools shall establish the leading group for education practice to ensure the full implementation of the education practice work.

\section{ESTABlish THE SYSTEM OF "CONTACT POINT AND CONTACT PERSON” AND STRENGTHEN THE EXCHANGE AND COMMUNICATIONS AMONG VARIOUS BASES TO ACHIEVE THE MUTUAL PROMOTION OF VARIOUS BASES}

The physical education institutes and departments could work as the organizer to hold friendly competitions of group sports program, competitions of open classes and so forth to strengthen the subjective identification to the function of physical education of the teachers and leaders of various bases. Moreover, the organization of such activities would also be beneficial for creating excellent atmosphere of physical education culture, making contributions for the "National Fitness Program" and strengthening the exchange and exercises with the practice bases.

\section{TAKE FUll AdVANTAGE OF THE MULTI-FUNCTION OF THE BASES}

To make full advantage of the multi-function of the practice bases shall refer to promote the transformation of the education practice bases from the closed type operation to the multi-function and multi-benefit development and utilization of the practice bases, and the shifting of the practice base from "still" bases to "live" bases. For examples, besides the acceptance of interns, the practice base of Hubei Normal University is also the education practice point, exercise points for young teachers, social investigation point, experimental site for teaching reform of middle school, and etc. Learning from this successful experience, the physical education institutes and departments shall conduct the cooperative teaching studies with the practice bases and explore the teaching reform for the education and physical education of higher education institutes. The cooperative studies on the teaching research programs between the physical education institutes or departments and the practice bases is beneficial for the exploration of the talent cultivation patterns of "sound foundation, broad caliber, application orientation and high quality" under the new situations of our country. The research programs may include the study and discussion about the teaching method for the "Physical Education and Health" under the new curriculum standards for middle schools, research on the development status and prospect of physical education in middle schools, and etc. The cooperation on these studies would not only increase the scientific research capacity of the teachers in bases, but also provide scientific research materials for the physical education teacher in higher education institutions and promote the application of the scientific research results about teaching study of middle school, which would thoroughly reflect the principles of mutual benefits and reciprocity.

\section{STRIVE TO ACHIEVE “THREE-PARTY” JOINT CONSTRUCTION OF PRACTICE BASES AMONG PHYSICAL EDUCATION INSTITUTES OR DEPARTMENT, EDUCATIONAL ADMINISTRATIVE AUTHORITY AND SCHOOL FOR INTERNSHIP}

It was found from the studies that the attention of the leaders of the education administrative authority was of great significance to the stability of education practice base. Therefore, it is necessary to actively strive to get their supports and make full advantages of their leading role and management functions. The physical education institutes and departments could promote the education administrative authority to set the construction of practice base as one of the assessment indicator for schools through documents to motivate the enthusiasm of the practice schools.

In order to improve the material conditions of the practice base, the physical education institutes or departments shall establish frequent communication system with the practice schools, and provide necessary supports and conveniences to the practice schools on the aspect of human resource, materials and financial. Meanwhile, appropriate training and examination directions shall also be arranged to the sports students in the practice schools. With the high quality teacher resources and high familiarity for the policies and strategies of physical education examination, the training and examination of directions delivered by the physical education institutes or departments would have great significance to the sports students in practice schools. The physical education institutes or departments could arrange their teachers to the practice schools to provide the instructions, or invite the sports students of base school to the higher education institution to accept the short-term intensive training under the supervision of the teachers of higher education institutions. The construction of education practice bases shall not solely confined to the sending of interns and inspections. Instead, the physical education institutes or departments shall perform communications with the functional departments to establish the cooperation relationship. Moreover, they shall undertake the tasks like the skill training for the teachers of the bases, the assistance to the sports meetings and competitions, directions for the school exercises and college entrance examinations, and the services and promotion of the teaching information and documents of physical education to achieve the mutual benefit and win-win of the cooperation with the practice schools. The physical education institutes or departments could get the information feedback on various aspects from the practice base through the construction of education bases. Meanwhile, the practice schools could continuously absorb the new teaching concepts, theories and methods to achieve excellent teaching results. 
Besides, the selection of practice bases shall break the conventions and stress more on actual benefits. As professional talents of physical education, the intern would inevitably influenced by the course arrangement, exam-oriented examination and social demand. During the cultivation of their practical abilities, it is necessary to consider where they would work in the future and what job they would take in the future.

Along with the development of the market economy and sports exercises and the continuous improvement of the living standards of the people, sports activities have become a major approach for the fitness of the mass and the communication sports and club sports have developed into certain scale. Under such situations, the positions of instructor of social sports fitness and instructor of club sports have great demand potential. The graduates from physical education departments would become the direct resources and main candidates for these two positions. Therefore, the practice shall take these two employment positions into considerations in the arrangement of the practice approaches.

On the aspect of practice arrangement, the physical education institutes or department could consider to closely link the university life with the social activities of the students majoring in physical education to ensure they would learn about the quality specification of the social demand for physical education talents. The diversified and wide range practice approaches shall replace the traditional practice approaches with the features of centralized time, centralized and single object.

\section{REFERENCES}

[1] Xu Kaichun, Liu Bingquan, Jiang Zhiqiang. Study and Thinking about the Education Practice Bases Construction of Physical education institutes or departments[J]. Journal of Shenyang Physical Education College, 2003, (3)

[2] Xu Kaichun. Studies on the Theories and Practices for the Improvement of the Quality and Benefits of Education Practice [M]. Shenyang: Liaohai Press, 2002, 11

[3] $\mathrm{Xu}$ Gaohou. Education Practice [M]. Beijing: Beijing Normal University Press, 1995

[4] Gao Zhi, Chen Xingsheng, Xu Qiong, Du Congxin, Zha Huanan, Wang Yufeng. Study on the Reform of the Education Practice for Physical Education [J]. Journal of Wuhan Physical Education College. 2002, (4)

[5] Chen Shu, Du Guangyou. Discussion about the Construction of Physical Education Practice Base [J]. Journal of Haerbin Physical Education College, 2005, (4)

[6] Li Xiangru. Study on the Education Practice Reform of the Higher Physical Education in Our Country [J]. Journal of Guangzhou Physical Education College, 2001, (6)

[7] Ba Yanfang, Guo Min. Study on the Construction of Physical Education Practice Bases under the New Situations [J]. Journal of Chengdu Education Institute, 2005 (10)

[8] $\mathrm{Xu}$ Shengxia, Guo Min. Exploration for the Construction of Physical Education Practice Bases under the New Situations [J]. Journal of Capital Institute of Physical Education, 2005.

[9] Ziwang Chen. Research on current situation and Countermeasures of $[\mathrm{J}]$. Journal of Beijing Sport University of China's sports departments of universities sports dance courses. 2006 (02)

[10] Ni Xin, Ye Wei. Analysis of additional sports dance teaching in college physical role [J]. sports and science. 2006 (03)

[11] Jiang Wei, Jia Baojian. Physical education in public colleges and universities offering the physical dance course examines $[\mathrm{J}]$. Journal of Beijing Sport University. 2006 (10)

[12] Hou Ye. affected the mental health of college students. On the two elements of [J]. youth literature. 2011 (02) 